Brazilian Journal
of Chemical
Engineering

\title{
MESOPOROUS MOLECULAR SIEVE MCM-41 SYNTHESIS FROM FLUORIDE MEDIA
}

\author{
F. S. Bastos, O. A. Lima, C. Raymundo Filho and L. D. Fernandes* \\ Departamento de Engenharia Química, Universidade Federal Rural do Rio de Janeiro, Fax: + (55) (21) 3787-3742, \\ BR-465, km 7, Seropédica, 23.890-000, RJ - Rio de Janeiro, Brazil. \\ E-mail: lindoval@ufrrj.br
}

(Submitted: December 20, 2010 ; Revised: May 4, 2011 ; Accepted: June 21, 2011)

\begin{abstract}
A study of the synthesis of MCM-41 mesoporous molecular sieves in fluoride media, having no alkaline metal ions, was performed by changing the gel composition and crystallization temperature and time. X-ray diffraction and nitrogen adsorption analyses showed that highly ordered MCM-41 samples were obtained from gels with a $\mathrm{NH}_{4} \mathrm{OH} / \mathrm{SiO}_{2}$ molar ratio in the 3.25-4.3 range (room temperature synthesis) or in the 4.3-20 range (24 hours at $373 \mathrm{~K}$ ). During calcination, unit cell shrinkage, caused by high temperature polycondensation of the $\mathrm{SiOH}$ groups, was observed for all samples. The samples synthesized at high temperature $(373 \mathrm{~K})$ or using low $\mathrm{pH}$ gels $(7.5)$ underwent lower unit cell shrinkage than those obtained at room temperature or high $\mathrm{pH}(9.0)$, indicating that the former samples had lower $\mathrm{SiOH}$ groups content than the latter. These highly-ordered samples showed large surface area (ca. $1100 \mathrm{~m}^{2} / \mathrm{g}$ ) and pore volume (ca. 0.80 $\mathrm{cm}^{3} / \mathrm{g}$ ), also presenting a narrow pore size distribution. Due to higher silicate polycondensation and a thicker pore wall, the samples synthesized at $373 \mathrm{~K}$ were more hydrothermally stable than those obtained at room temperature.
\end{abstract}

Keywords: Mesoporous silica; MCM-41; Fluoride medium; Mesoporous molecular sieves; M41S.

\section{INTRODUCTION}

Mobil scientists discovered a new family of porous materials, presenting a regular array of uniform mesopores, in 1992 (Beck et al, 1992 and Kresge et al., 1992). This family of materials, named M41S, was composed of three phase types: one with hexagonal $P 6 \mathrm{~mm}$ symmetry (MCM-41), presenting a monodirectional pore system, a second phase with cubic Ia3d symmetry (MCM-48), showing a three directional pore system, and a third lamellar phase (MCM-50), that collapses when submitted to high temperature calcination to remove the organic template (Ciesla et al., 1999, Corma, 1997, Biz et al., 1998 and Sayari, 1996). Among the stable phases, MCM-41 is the most studied due to the relative facility of its synthesis. The MCM-41 structure is formed by a hexagonal array of silica tubes, like a honeycomb. Even though these materials present long-range ordering, as envisaged by small angle $\mathrm{X}$ ray diffraction or by transmission electron microscopy, they have no short distance ordering, i.e., the pore walls are formed by amorphous silica.

One of the challenges in M41S material syntheses is preparing hydrothermally stable samples. Ryoo et al. $(1997 ; 1998)$ reported that these materials support thermal treatments at temperatures higher than $1000 \mathrm{~K}$. However, under hydrothermal conditions they present very low stability. Even hot aqueous solution treatments or atmospheric moisture exposure for a long period of time were sufficient to promote a total or partial collapse of the MCM-41 structure (Ribeiro-Carrott et al., 1999). This low hydrothermal stability probably was due to the presence of non-condensed $\mathrm{SiOH}$ units in the MCM-41 structure. Recently, Voegtlin et al. (1997a) studied MCM-41 synthesis in fluoride media at room temperature, using

*To whom correspondence should be addressed 
ammonium hexafluorosilicate as fluoride precursor. They reported evidence that the samples synthesized using low $\mathrm{pH}$ gels $(\mathrm{pH}=8.0)$ presented relatively low amounts of $\mathrm{SiOH}$ groups. It is well known that zeolite synthesis from neutral or near neutral $\mathrm{pH}$ gels, using fluoride ion as the mineralizing agent, produces samples with lower amounts of defect sites in their structure $(\mathrm{SiOH}$ groups) than samples synthesized from alkaline gels (Guth, 1993). On the other hand, Pastore et al. (1999) and Silva et al. (1996) obtained MCM-41 samples from gels containing hydrofluoric acid as precursor of the fluoride ion, which presented normal amounts of $\mathrm{SiOH}$ groups. However, they worked under alkaline conditions where, according to Voegtlin et al. (1997a), the fluoride ion does not have significant effects on $\mathrm{SiOH}$ groups content. Xia et al. (2000) and Kim et al. (2000) reported the synthesis of hydrothermally stable MCM-41 samples in fluoride media with a $\mathrm{pH}$ range between $10-10.5$, using $\mathrm{NaF}$ and $\mathrm{HF}$ as fluoride precursors. $\mathrm{Xu}$ et al. (2002) and Luque et al. (2005) studied $\mathrm{NH}_{4} \mathrm{~F}$ post-synthesis addition aiming at improving hydrothermal stability and the acid properties. In this context, the main objective of this work is to study MCM-41 synthesis in fluoride media using a wider range of operating conditions than Voegtlin et al. (1997a). To this end, syntheses were conducted under several $\mathrm{pH}$ conditions, varying the dilution of the gel and the synthesis time and temperature.

\section{EXPERIMENTAL}

\section{Synthesis}

The following reagents were used in sample preparations: cetyltrimethylammonium bromide (CTABr, Fluka), ammonium hexafluorosilicate $\left(\left(\mathrm{NH}_{4}\right)_{2} \mathrm{SiF}_{6}\right.$, Fluka), ammonium hydroxide $\left(\mathrm{NH}_{4} \mathrm{OH}\right.$, Reagen). The synthesis experiments were based on Voegtlin et al. (1997a), but gel composition and synthesis time and temperature were also changed. Gels presenting the following molar composition: $1.0 \quad \mathrm{SiO}_{2}: 0.215 \mathrm{CTABr}: 0.5-20$ $\mathrm{NH}_{4} \mathrm{OH}: 50-1500 \mathrm{H}_{2} \mathrm{O}$ were prepared. In a typical synthesis experiment, solution A was prepared by dissolving CTABr and $\left(\mathrm{NH}_{4}\right)_{2} \mathrm{SiF}_{6}$ in half of the total amount of deionized water; for solution $\mathrm{B}$ preparation, $\mathrm{NH}_{4} \mathrm{OH}$ was mixed with the remaining deionized water. Then, solution A was slowly added to solution B under magnetic stirring. This mixture was stirred for 60 minutes at room temperature. The resulting slurry was filtered, washed with hot deionized water and dried in a stove at $373 \mathrm{~K}$ overnight, forming the samples synthesized at room temperature. After being stirred during 60 minutes at room temperature, the slurry was placed in a Teflon-lined stainless steel autoclave and heated at $373 \mathrm{~K}$ for 24 hours, characterizing the high temperature synthesis, then cooled and filtered like the sample prepared at room temperature. To remove the surfactant, all the assynthesized samples were calcined in air under static conditions at $813 \mathrm{~K}$ for 6 hours, with a linear temperature ramp of $0.5 \mathrm{~K} / \mathrm{min}$.

\section{Characterization}

Powder X-ray diffraction (XRD) patterns were recorded on a Rigaku Miniflex diffractometer using $\mathrm{CuK} \alpha$ radiation and operating at $30 \mathrm{kV}$ and $15 \mathrm{~A}$. Typically, the XRD data were collected from 1.2 to $10^{\circ}(2 \theta)$ with $0.02^{\circ}$ step size and $2 \mathrm{~s}$ step time.

The nitrogen adsorption and desorption isotherms at $77 \mathrm{~K}$ were measured using a Micromeritics ASAP2400 system. Before the measurements, the samples were outgassed at $573 \mathrm{~K}$ during 3 hours in the degas port of the adsorption analyzer. From these isotherms, the surface area was calculated by the BET method (Brunauer et al. 1938), while pore volume and pore size distribution were determined by the t-plot and Barrett, Joyner and Halenda (BJH) methods (Lippens et al., 1964 and Barrer et al., 1951), respectively. Equation (1), proposed by Kruk et al. (1997a), was used to yield the statistical multilayer thickness. Pore size distribution was also determined by the BJH method modified by Kruk, Jaroniec and Sayari (Kruk et al., 1997a, Kruk et al., 1999 and Kruk et al., 1997b) (BJH-KJS) and by Broekhoff-deBoer (BdB) analysis using a FrenkelHalsey-Hill equation to describe the statistical multilayer thickness (Lukens et al., 1999). All methods for determining pore size distribution used the adsorption branch of the isotherm.

$\mathrm{t}=\left\{\frac{60.65}{0.03071-\log \left(\mathrm{P} / \mathrm{P}_{\mathrm{o}}\right)}\right\}^{0.3968}$

In order to test the hydrothermal stability of the samples, they were slurred ( $1 \mathrm{wt} \%$ of solids) in a buffer solution of ammonium acetate $(\mathrm{pH}=7.0)$ and kept at $373 \mathrm{~K}$ during 24 hours following a procedure adapted from Kim et al. (2000) and Xia et al. (2000) with buffer addition to keep the $\mathrm{pH}$ constant. After this time, the samples were recovered by filtration, washed 
with hot deionized water and dried at $373 \mathrm{~K}$ overnight. X-ray diffraction patterns (XRD) of the samples, before and after this treatment, were compared to estimate the extension of the structural collapse.

\section{RESULTS AND DISCUSSION}

The procedure of Voegtlin et al. (1997a) was performed using a gel with the following molar composition: $1.0 \mathrm{SiO}_{2}: 0.215 \mathrm{CTABr}: 4.3 \mathrm{NH}_{4} \mathrm{OH}: 300$ $\mathrm{H}_{2} \mathrm{O}$. The sample recovered from this experiment presented X-ray diffraction (XRD) patterns typical of a highly ordered MCM-41 phase. Indeed, the diffractogram revealed five peaks, assigned to the MCM-41 hexagonal P6mm structure: (100), (110), (200), (210) and (300). The nitrogen adsorption/ desorption isotherm was a type IV one, having no hysteresis loop. This isotherm was characterized by an adsorption step at low relative pressure (P/Po ca. 0.27), followed by an almost horizontal branch. The adsorption step was due to capillary condensation in uniform size mesopores. After mesopore filling, multilayer adsorption on the sample external surface took place. From this isotherm, a surface area of $1100 \mathrm{~m}^{2} / \mathrm{g}$ and a primary mesopore volume of $0.77 \mathrm{~cm}^{3} / \mathrm{g}$ was determined for this sample. Pore size distribution determined by the Broekhoff-deBoer

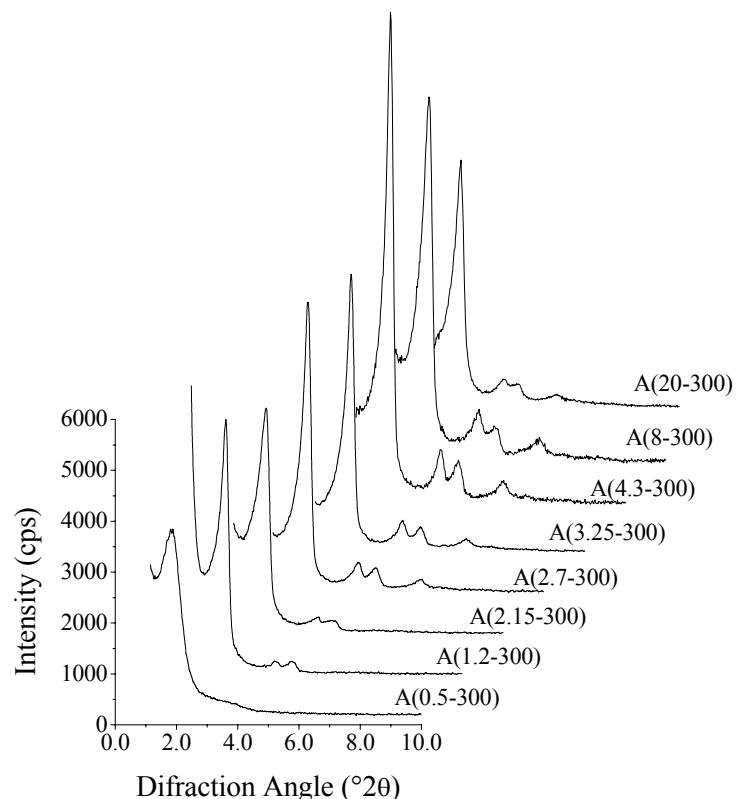

(a)

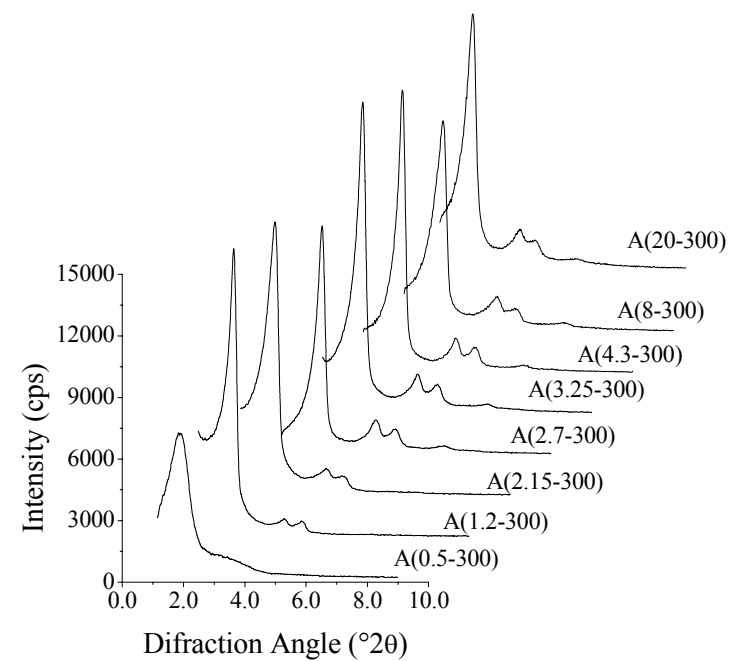

(b)

Figure 1: XRD patterns of MCM-41 samples synthesized at room temperature changing synthesis gel $\mathrm{NH}_{4} \mathrm{OH} / \mathrm{SiO}_{2}$ molar ratio while keeping the $\mathrm{H}_{2} \mathrm{O} / \mathrm{SiO}_{2}$ molar ratio constant at 300 . The samples were denoted $\mathrm{A}(\mathrm{x}-\mathrm{y})$, where $\mathrm{x}$ and $\mathrm{y}$ represent the gel synthesis $\mathrm{NH}_{4} \mathrm{OH} / \mathrm{SiO}_{2}$ and $\mathrm{H}_{2} \mathrm{O} / \mathrm{SiO}_{2}$ molar ratios, respectively. (a) As-synthesized samples. (b) Calcined samples. 
Table 1: X-ray diffraction data for the MCM-41 samples and the values of the synthesis gel pH.

\begin{tabular}{|c|c|c|c|c|}
\hline \multirow{2}{*}{ Sample } & \multicolumn{3}{|c|}{ Interplanar distance $d_{(100)}(\AA)$} & \multirow{2}{*}{ gel pH } \\
\hline & As-synthesized & Calcined & Unit cell shrinkage (\%) & \\
\hline $\mathrm{A}(0.5-300)$ & 46.7 & - & - & 6.2 \\
\hline $\mathrm{A}(1.2-300)$ & 38.5 & 38.2 & 0.9 & 7.5 \\
\hline $\mathrm{A}(2.15-300)$ & 38.7 & 37.7 & 2.6 & 7.7 \\
\hline $\mathrm{A}(2.70-300)$ & 38.2 & 35.0 & 8.1 & 8.8 \\
\hline $\mathrm{A}(3.25-300)$ & 37.1 & 34.7 & 6.7 & 9.2 \\
\hline $\mathrm{A}(4.3-300)$ & 37.7 & 35.6 & 6.0 & 9.5 \\
\hline $\mathrm{A}(8.0-300)$ & 39.2 & 35.6 & 10.2 & 10.0 \\
\hline $\mathrm{A}(20-300)$ & 41.3 & 37.9 & 8.9 & 10.6 \\
\hline $\mathrm{B}(2.15-300)$ & - & - & - & 7.7 \\
\hline $\mathrm{B}(2.70-300)$ & 39.2 & - & - & 8.8 \\
\hline $\mathrm{B}(3.25-300)$ & 39.4 & - & - & 9.2 \\
\hline $\mathrm{B}(4.3-300)$ & 39.1 & 38.0 & 2.6 & 9.5 \\
\hline $\mathrm{B}(8.0-300)$ & 39.6 & 38.0 & 4.0 & 10.0 \\
\hline $\mathrm{B}(20-300)$ & 40.9 & 40.3 & 1.4 & 10.6 \\
\hline
\end{tabular}

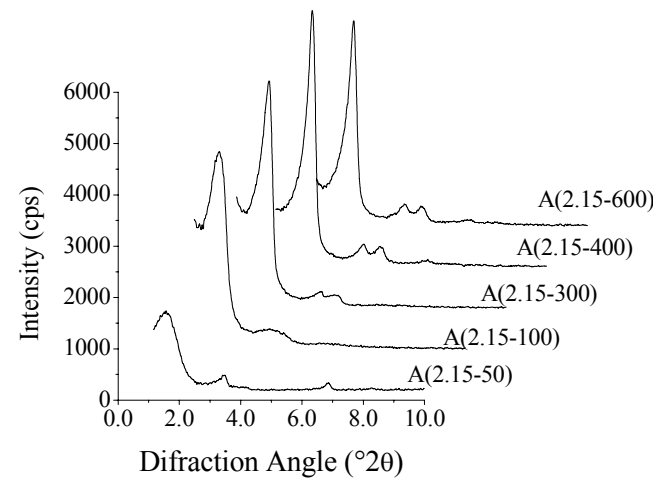

(a)

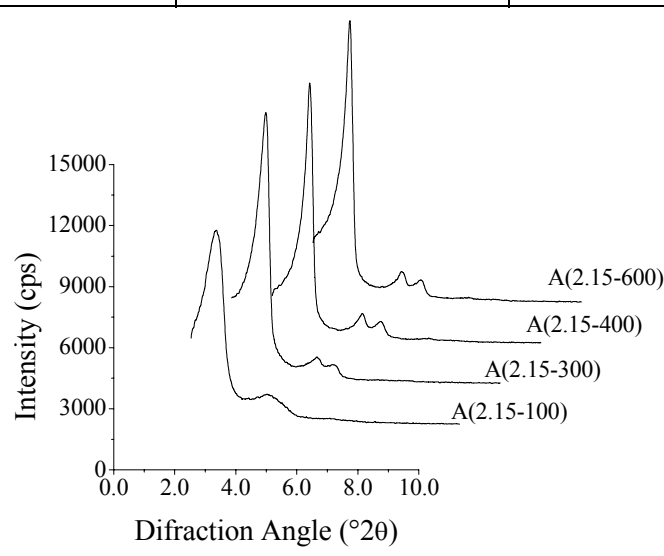

(b)

Figure 2: XRD patterns of MCM-41 samples synthesized at room temperature changing synthesis gel $\mathrm{H}_{2} \mathrm{O} / \mathrm{SiO}_{2}$ molar ratio while keeping the $\mathrm{NH}_{4} \mathrm{OH} / \mathrm{SiO}_{2}$ molar ratio constant at 2.15 . The samples were denoted $\mathrm{A}(\mathrm{x}-\mathrm{y})$, where $\mathrm{x}$ and $\mathrm{y}$ represent the gel synthesis $\mathrm{NH}_{4} \mathrm{OH} / \mathrm{SiO}_{2}$ and $\mathrm{H}_{2} \mathrm{O} / \mathrm{SiO}_{2}$ molar ratios, respectively. (a) As-synthesized samples. (b) Calcined samples.

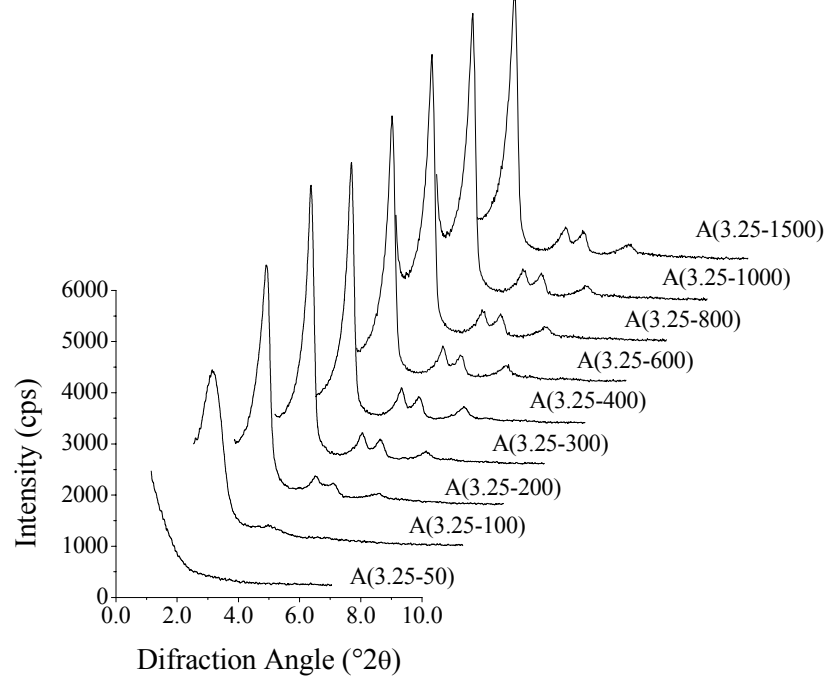

(a)

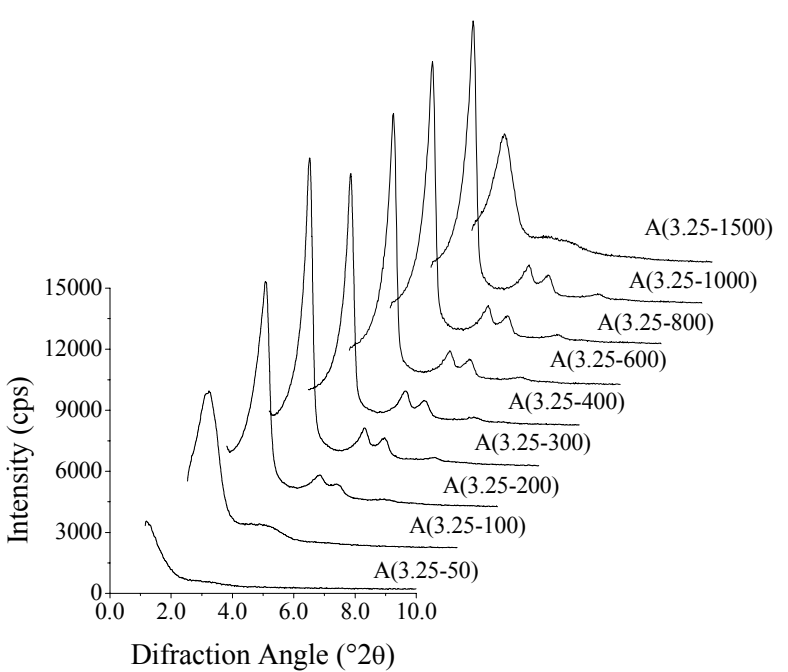

(b)

Figure 3: XRD patterns of MCM-41 samples synthesized at room temperature changing the synthesis gel $\mathrm{H}_{2} \mathrm{O} / \mathrm{SiO}_{2}$ molar ratio while keeping the $\mathrm{NH}_{4} \mathrm{OH} / \mathrm{SiO}_{2}$ molar ratio constant at 3.25. The samples were denoted $\mathrm{A}(\mathrm{x}-\mathrm{y})$, where $\mathrm{x}$ and $\mathrm{y}$ represent the gel synthesis $\mathrm{NH}_{4} \mathrm{OH} / \mathrm{SiO}_{2}$ and $\mathrm{H}_{2} \mathrm{O} / \mathrm{SiO}_{2}$ molar ratios, respectively. (a) As-synthesized samples. (b) Calcined samples. 
Figure 2 shows that highly ordered samples were recovered from gels with $\mathrm{H}_{2} \mathrm{O} / \mathrm{SiO}_{2}$ molar ratios in the 400-600 range. From more concentrated gels, mesophases with a low degree of order were formed. Samples showing a high degree of ordering were recovered from gels with $\mathrm{H}_{2} \mathrm{O} / \mathrm{SiO}_{2}$ molar ratios in the 200-1000 range (Figure 3). It was observed that the use of concentrated synthesis gels produced amorphous phases or mesophases with low structural ordering.

Figure 4 presents nitrogen adsorption isotherms and pore size distributions, determined by Broekhoff-deBoer (BdB) analysis using a FrenkelHalsey-Hill equation to describe the statistical multilayer thickness (Lukens et al., 1999) of the samples obtained by room temperature synthesis. The textural characterization was determined using the nitrogen isotherms (Table 2).

Figure 4 presents nitrogen adsorption isotherms for samples obtained by room temperature synthesis, using gels with low $\mathrm{NH}_{4} \mathrm{OH} / \mathrm{SiO}_{2}$ molar ratios (2.15 or smaller); these presented only a small adsorption step at a relative pressure of about 0.26 , indicating a low contribution of uniform size primary mesopores. The presence of a hysteresis loop and the slow increase in the amount adsorbed at relative pressures higher than 0.5 indicate the presence of non-uniform size secondary mesopores. As the synthesis gel $\mathrm{NH}_{4} \mathrm{OH}$ content was increased, the adsorption step at a relative pressure of ca. 0.26 in the nitrogen isotherms also increased, but the additional amount adsorbed at higher relative pressure $(\mathrm{P} / \mathrm{Po}>0.5)$ decreased, while the hysteresis loop vanished. This indicated that the primary mesopore volume increased while the secondary mesopores decreased. In fact, from Table 2, it can be noted that the secondary mesopore contribution to the total mesopore volume decreased as the synthesis gel $\mathrm{NH}_{4} \mathrm{OH}$ content increased, as can be seen by comparing the pore volume values from $\mathrm{BJH}$ analysis (total mesoporosity) to the t-plot method (primary mesopores). On the other hand, samples prepared with $\mathrm{NH}_{4} \mathrm{OH} / \mathrm{SiO}_{2}$ ratios higher than 8 presented nitrogen isotherms with practically no adsorption step at a relative pressure of ca. 0.26, indicating almost the absence of primary mesopores. In fact, Table 2 shows that these samples presented relatively low values of surface area and primary mesopore volume.

The samples recovered from gels with $\mathrm{NH} 4 \mathrm{OH} / \mathrm{SiO} 2$ molar ratios in the 3.25-4.3 range presented very narrow pore size distributions with a maximum at ca. $27 \AA$ when Broekhoff-deBoer analysis was employed (Figure 4).

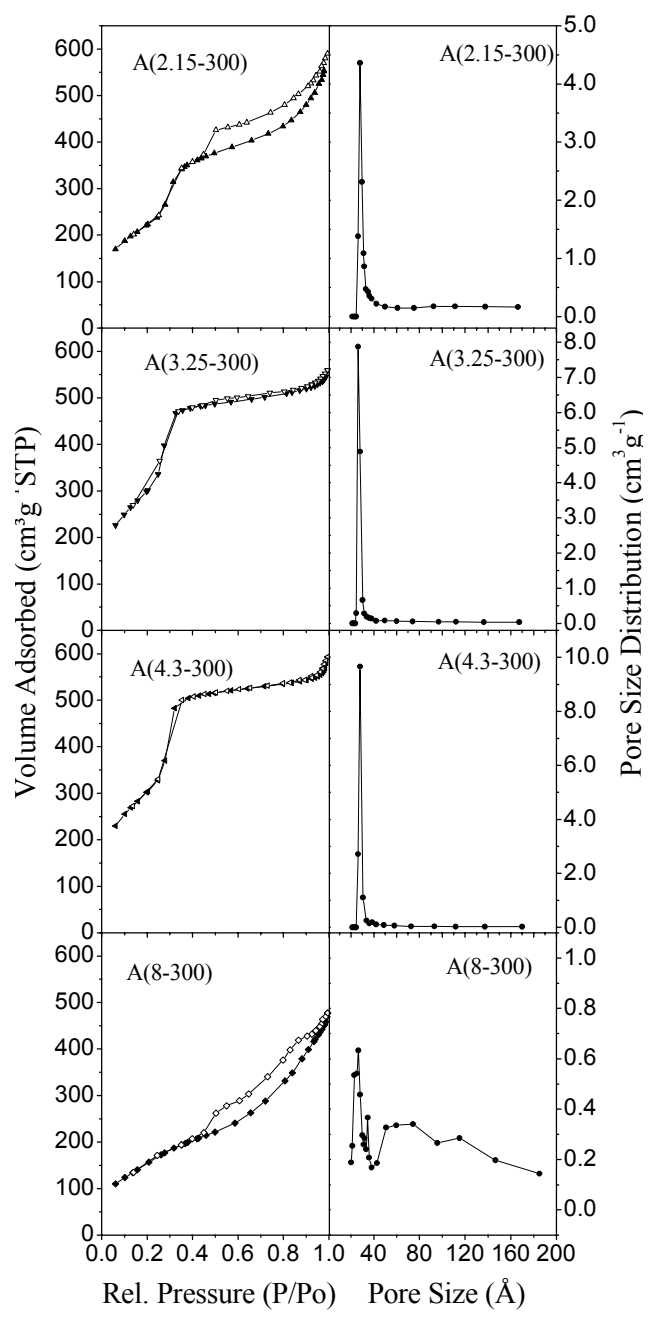

Figure 4: Nitrogen adsorption (closed symbols) and desorption (open symbols) isotherms and pore size distributions determined by Broekhoff-deBoer analysis using a Frenkel-Halsey-Hill equation to describe the statistical multilayer thickness (Lukens et al. 1999) of the room temperature synthesized samples.

The remaining samples presented broad pore size distributions, with the contribution of secondary mesopores with diameters larger than $100 \AA$. In particular, the $A(8-300)$ sample presented mesopores with pore diameters covering the entire $20-500 \AA$ range, suggesting a low degree of ordering. Table 2 presents the pore volumes and diameters of the samples determined by three different methods, i.e., BJH, BJH modified by Kruk, Jaroniec and Sayari and Broekhoff-deBoer. All methods gave similar tendencies, although presenting some differences in the pore volume and diameter values.

The nitrogen adsorption data and the X-ray diffraction analyses indicated that samples obtained from gels with $\mathrm{NH}_{4} \mathrm{OH} / \mathrm{SiO}_{2}$ molar ratios in the 3.254.3 range presented a high degree of ordering. 
Table 2: Textural characterization of the MCM-41 samples from nitrogen physisorption isotherms.

\begin{tabular}{|c|c|c|c|c|c|c|c|c|c|}
\hline \multirow{3}{*}{ Sample } & \multirow{3}{*}{$\begin{array}{l}\text { BET surface } \\
\text { area }\left(\mathrm{m}^{2} / \mathrm{g}\right)\end{array}$} & \multirow{3}{*}{$\begin{array}{c}\text { Primary } \\
\text { mesopore } \\
\text { volume } \\
\left(\mathrm{cm}^{3} / \mathbf{g}\right)^{(1)}\end{array}$} & \multirow{3}{*}{$\mathbf{b}(\AA)^{(2)}$} & \multicolumn{6}{|c|}{ Mesopore volume and diameter } \\
\hline & & & & \multicolumn{2}{|c|}{ BJH } & \multicolumn{2}{|c|}{ BJH-KJS } & \multicolumn{2}{|c|}{ Broekhoff-deBoer } \\
\hline & & & & $\begin{array}{l}\begin{array}{l}\text { Volume } \\
\left(\mathrm{cm}^{3} / \mathrm{g}\right)\end{array} \\
\end{array}$ & $\begin{array}{c}\text { Diameter } \\
(\AA)\end{array}$ & $\begin{array}{l}\text { Volume } \\
\left(\mathrm{cm}^{3} / \mathrm{g}\right)\end{array}$ & $\begin{array}{c}\text { Diameter } \\
(\AA)\end{array}$ & $\begin{array}{l}\text { Volume } \\
\left(\mathrm{cm}^{3} / \mathrm{g}\right)\end{array}$ & $\begin{array}{c}\text { Diameter } \\
(\AA)\end{array}$ \\
\hline $\mathrm{A}(2.15-300)$ & 804 & 0.38 & 12.5 & 0.94 & 25.4 & 1.12 & 34.6 & 0.96 & 28.0 \\
\hline $\mathrm{A}(3.25-300)$ & 1093 & 0.71 & 11.1 & 0.84 & 23.5 & 1.10 & 34.8 & 1.00 & 26.4 \\
\hline $\mathrm{A}(4.3-300)$ & 1101 & 0.77 & 10.6 & 0.92 & 25.5 & 1.17 & 34.7 & 1.10 & 28.1 \\
\hline $\mathrm{A}(8-300)$ & 576 & 0.04 & 14.2 & 0.73 & 23.9 & 0.91 & 28.5 & 0.75 & 26.7 \\
\hline $\mathrm{A}(3.25-600)$ & 1014 & 0.56 & 15.4 & 0.45 & 23.7 & 0.70 & 32.9 & 0.62 & 26.5 \\
\hline $\mathrm{B}(2.15-300)$ & 350 & 0.08 & - & 0.43 & 20.4 & 0.52 & 31.0 & 0.45 & 25.0 \\
\hline $\mathrm{B}(3.25-300)$ & 546 & 0.17 & - & 0.52 & 21.8 & 0.68 & 31.0 & 0.59 & 24.9 \\
\hline $\mathrm{B}(4.3-400)$ & 647 & 0.35 & 16.9 & 0.52 & 23.7 & 0.68 & 30.9 & 0.64 & 26.6 \\
\hline $\mathrm{B}(8-300)$ & 703 & 0.41 & 16.6 & 0.57 & 23.6 & 0.74 & 34.9 & 0.66 & 28.2 \\
\hline $\mathrm{B}(20-300)$ & 806 & 0.56 & 15.4 & 0.76 & 28.6 & 0.94 & 36.9 & 0.80 & 30.6 \\
\hline $\mathrm{B}(3.25-600)$ & 641 & 0.28 & 17.9 & 0.46 & 22.0 & 0.65 & 31.1 & 0.60 & 25.0 \\
\hline
\end{tabular}

${ }^{1}$ Determined by t-plot (Lippens et al., 1964)

${ }^{2}$ Pore wall thickness determined by geometrical considerations (Krugk et al., 2000)

However, while nitrogen adsorption data suggested that samples prepared using a high $\mathrm{NH}_{4} \mathrm{OH}$ concentration $(\mathrm{A}(8-300))$ displayed low structural ordering, the X-ray diffraction analysis indicated that this sample had a highly ordered MCM-41 structure (see Figures 1.b and 4). This can be explained by the collapse of some of the silica walls between two or more pores, generating a wider pore, but keeping some kind of long range ordering.

The results from X-ray diffraction characterization of the MCM-41 samples are presented in Table 1, as well as the $\mathrm{pH}$ values presented by the synthesis gels. All samples, which presented some kind of structural ordering, underwent unit cell shrinkage during the calcination carried out to remove the organic template. This shrinkage took place due to $\mathrm{SiOH}$

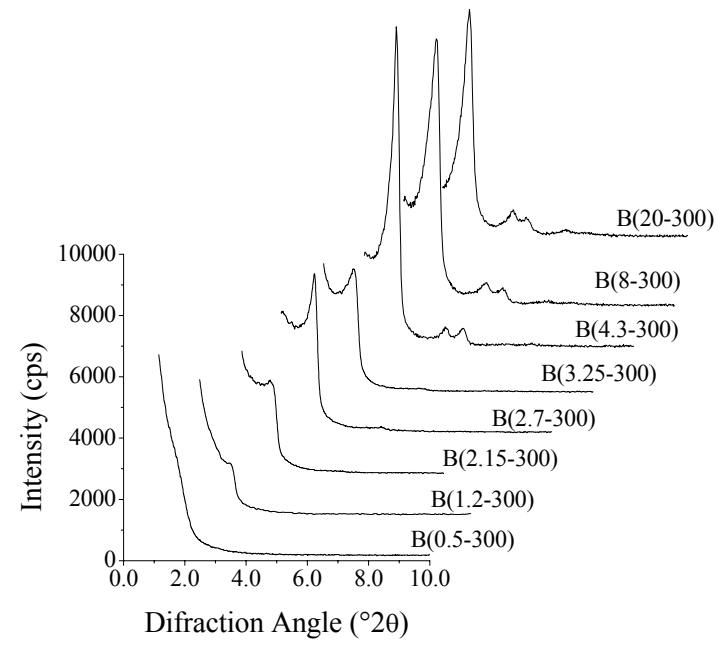

(a) polycondensation at high temperature. Samples synthesized at room temperature from gels having high $\mathrm{pH}$ values $(>10.0)$ underwent greater unit cell shrinkage than those synthesized using low gel $\mathrm{pH}$ values $(<9.0)$. This lower shrinkage indicated that these samples presented fewer non-condensed $\mathrm{SiOH}$ groups, i.e., silicate polycondensation was favored by low $\mathrm{pH}$ conditions, as already reported by Voegtlin et al. (1997b). A unit cell shrinkage comparison also indicated that the high temperature synthesized samples presented lower values than the room temperature samples.

Figure 5 presents the XRD patterns of the samples synthesized at $373 \mathrm{~K}$ during 24 hours by changing the gel $\mathrm{NH}_{4} \mathrm{OH} / \mathrm{SiO}_{2}$ molar ratio while keeping the $\mathrm{H}_{2} \mathrm{O} / \mathrm{SiO}_{2}$ molar ratio constant and equal to 300 .

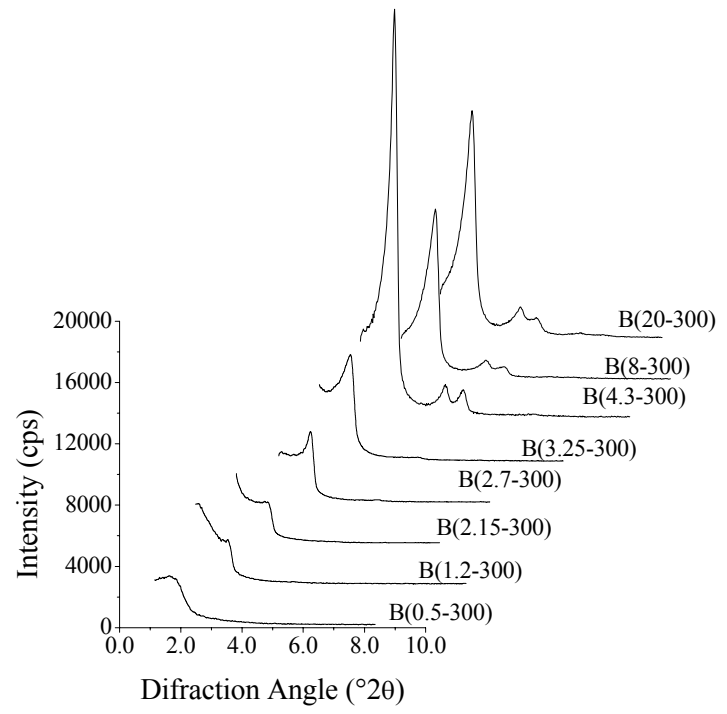

(b)

Figure 5: XRD patterns of MCM-41 samples synthesized at $373 \mathrm{~K}$ during 24 hours changing the synthesis gel $\mathrm{NH}_{4} \mathrm{OH} / \mathrm{SiO}_{2}$ molar ratio while keeping the $\mathrm{H}_{2} \mathrm{O} / \mathrm{SiO}_{2}$ molar ratio constant at 300 . The samples were denoted $\mathrm{B}(\mathrm{x}-\mathrm{y})$, where $\mathrm{x}$ and $\mathrm{y}$ represent the gel synthesis $\mathrm{NH}_{4} \mathrm{OH} / \mathrm{SiO}_{2}$ and $\mathrm{H}_{2} \mathrm{O} / \mathrm{SiO}_{2}$ molar ratios, respectively. (a) As-synthesized samples. (b) Calcined samples. 
The samples were denoted $\mathrm{B}(\mathrm{x}-\mathrm{y})$, where $\mathrm{x}$ and $\mathrm{y}$ represent the synthesis gel $\mathrm{NH}_{4} \mathrm{OH} / \mathrm{SiO}_{2}$ and $\mathrm{H}_{2} \mathrm{O} / \mathrm{SiO}_{2}$ molar ratios, respectively. From this figure, it can be observed that highly ordered MCM-41 samples can only be obtained from gels presenting $\mathrm{NH}_{4} \mathrm{OH} / \mathrm{SiO}_{2}$ molar ratios in the 4.3-20 range. From gels with lower $\mathrm{NH}_{4} \mathrm{OH}$ content, amorphous phases or low ordered mesophases were obtained.

Figures 6 and 7 present XRD patterns of the samples obtained from syntheses carried out by changing the gel $\mathrm{NH}_{4} \mathrm{OH} / \mathrm{SiO}_{2}$ molar ratio while keeping the gel $\mathrm{H}_{2} \mathrm{O} / \mathrm{SiO}_{2}$ molar ratio constant and equal to 2.15 (Figure 6) or 3.25 (Figure 7). From these figures, it can be observed that almost all samples prepared with a small $\mathrm{NH}_{4} \mathrm{OH}$ gel content possessed a low degree of structural ordering. Figure 8 shows that more dilute gels yielded more ordered mesophases, as illustrated by the MCM-41 structure using gels with a $\mathrm{H}_{2} \mathrm{O} / \mathrm{SiO}_{2}$ molar ratio between 400 and 1500 .

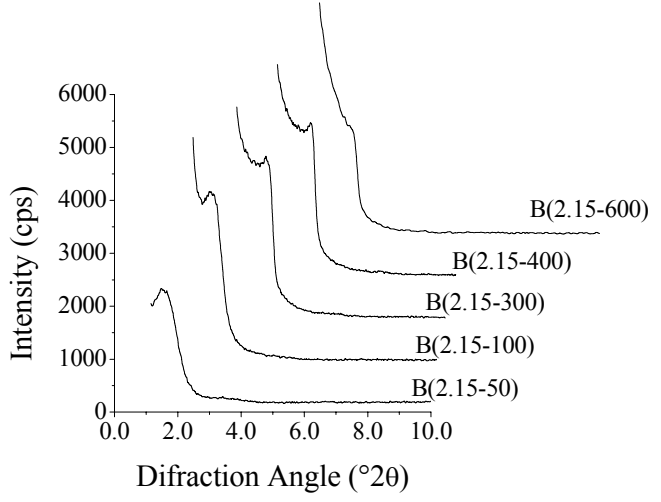

(a)

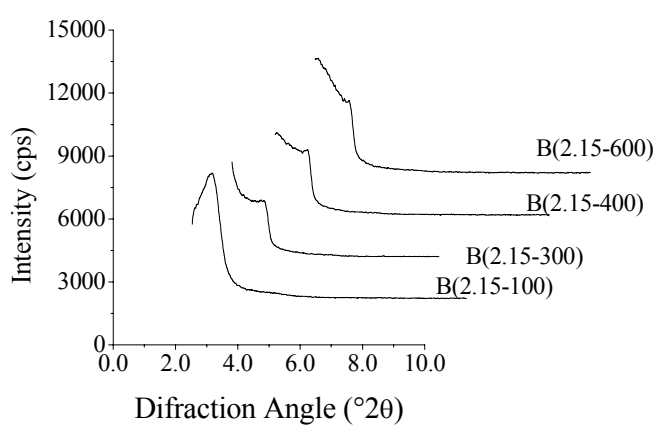

(b)

Figure 6: XRD patterns of MCM-41 samples synthesized at $373 \mathrm{~K}$ during 24 hours changing the synthesis gel $\mathrm{H}_{2} \mathrm{O} / \mathrm{SiO}_{2}$ molar ratio while keeping the $\mathrm{NH}_{4} \mathrm{OH} / \mathrm{SiO}_{2}$ molar ratio constant at 2.15. The samples were denoted $\mathrm{B}(\mathrm{x}-\mathrm{y})$, where $\mathrm{x}$ and $\mathrm{y}$ represent the gel synthesis $\mathrm{NH}_{4} \mathrm{OH} / \mathrm{SiO}_{2}$ and $\mathrm{H}_{2} \mathrm{O} / \mathrm{SiO}_{2}$ molar ratios, respectively. (a) As-synthesized samples. (b) Calcined samples.

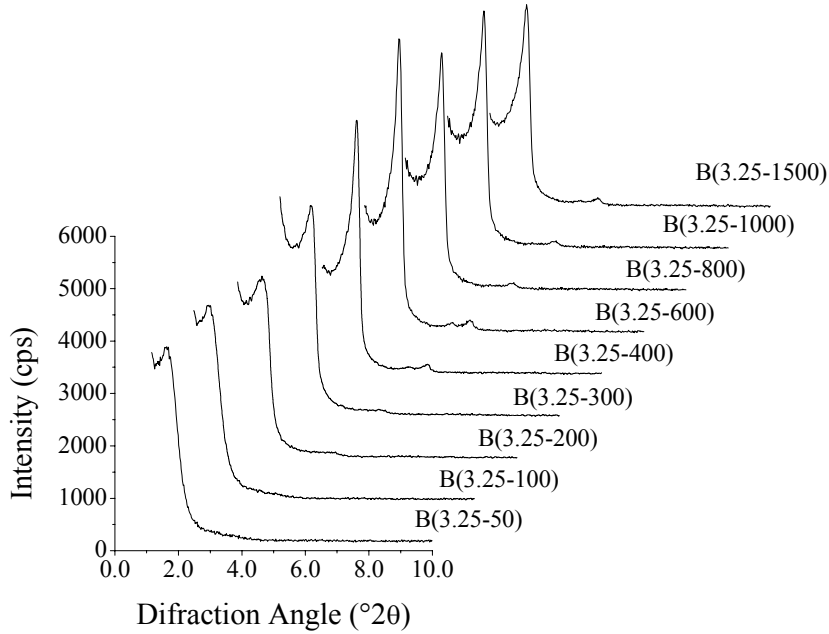

(a)

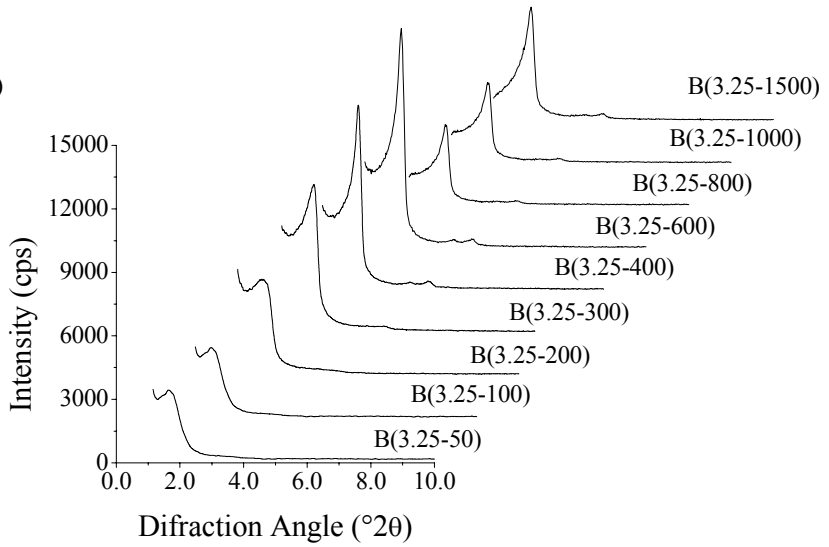

(b)

Figure 7: XRD patterns of MCM-41 samples synthesized at $373 \mathrm{~K}$ during 24 hours changing the synthesis gel $\mathrm{H}_{2} \mathrm{O} / \mathrm{SiO}_{2}$ molar ratio while keeping the $\mathrm{NH}_{4} \mathrm{OH} / \mathrm{SiO}_{2}$ molar ratio constant at 3.25. The samples were denoted $\mathrm{B}(\mathrm{x}-\mathrm{y})$, where $\mathrm{x}$ and $\mathrm{y}$ represent the gel synthesis $\mathrm{NH}_{4} \mathrm{OH} / \mathrm{SiO}_{2}$ and $\mathrm{H}_{2} \mathrm{O} / \mathrm{SiO}_{2}$ molar ratios, respectively. (a) As-synthesized samples. (b) Calcined samples. 


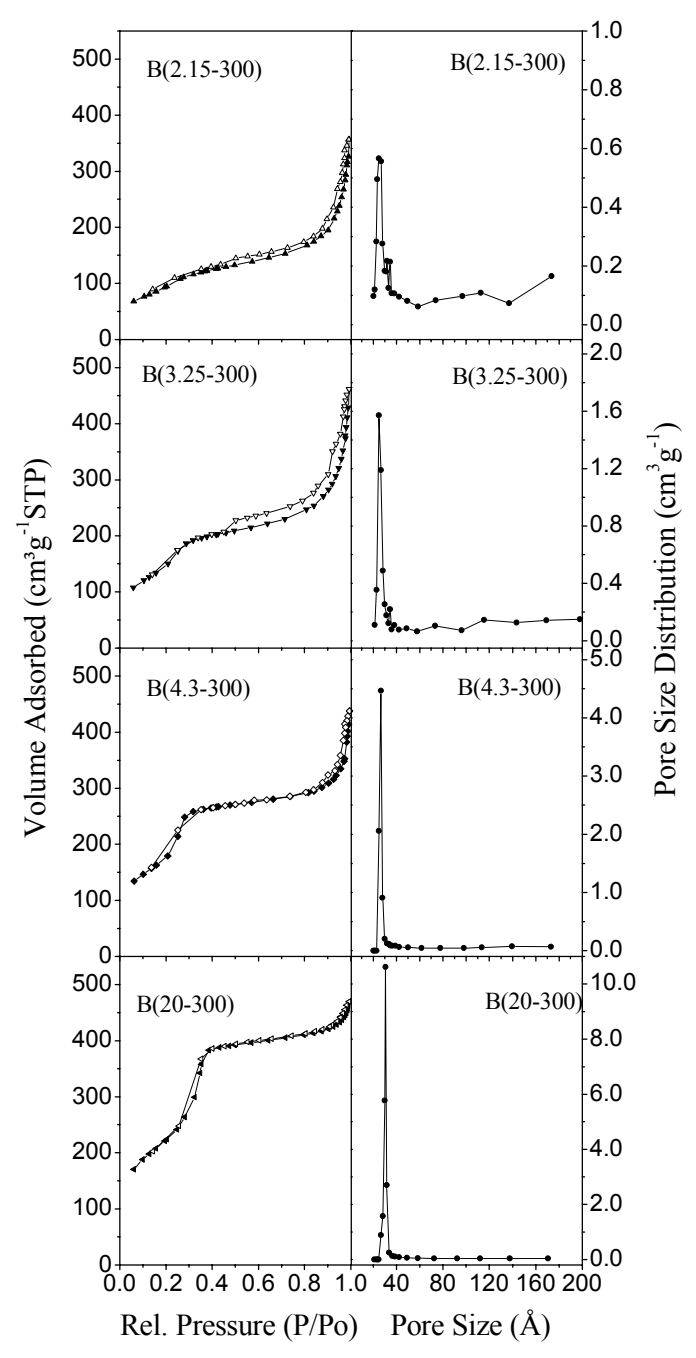

Figure 8: Nitrogen adsorption (closed symbols) and desorption (open symbols) isotherms and pore size distributions determined by Broekhoff-deBoer analysis with a Frenkel-Halsey-Hill equation to describe the statistical multilayer thickness (Lukens et al. 1999) of the samples synthesized at $373 \mathrm{~K}$ during 24 hours.

Figure 8 presents the nitrogen adsorption isotherms and pore size distribution of the samples synthesized at $373 \mathrm{~K}$ during 24 hours employing Broekhoff-deBoer analysis and a Frenkel-HalseyHill equation to describe the statistical multilayer thickness (Lukens et al., 1999). The nitrogen adsorption isotherms of the samples prepared with low $\mathrm{NH}_{4} \mathrm{OH} / \mathrm{SiO}_{2}$ molar ratio gels (3.25 or lower) showed practically no adsorption step at low relative pressure $(\mathrm{P} / \mathrm{Po}=0.2-0.4)$ (Figure 8$)$. A slow increase in the adsorbed amount at high relative pressure $(\mathrm{P} / \mathrm{Po}>0.5)$ and a hysteresis loop were observed, charactering the presence of non-uniform size secondary mesopores. As the synthesis gel $\mathrm{NH}_{4} \mathrm{OH}$ content was increased, the adsorption step in the nitrogen isotherms, at a relative pressure of ca. 0.26 , also increased; in addition, the additional adsorbed amount at higher relative pressure $(\mathrm{P} / \mathrm{Po}>0.5)$ decreased and the hysteresis loop vanished. This indicated that the primary mesopore volume increased while the secondary decreased. Indeed, from Table 2, it can be noted that the secondary mesopore contribution to the total mesopore volume decreased when the synthesis gel $\mathrm{NH}_{4} \mathrm{OH}$ content increased, as confirmed through BJH analysis (total mesoporosity) and t-plot method (primary mesopores) pore volume comparisons.

Samples B(8-300) and B(20-300) presented a very sharp pore size distribution with a maximum at ca. $27 \AA$ using Broekhoff-deBoer analysis. The remaining $373 \mathrm{~K}$ synthesized samples presented broader pore size distributions, with an appreciable contribution of secondary mesopores presenting diameters larger than $100 \AA$. The samples synthesized at $373 \mathrm{~K}$ presented lower surface areas and pore volume values than the samples synthesized at room temperature. This might occur because thicker pore wall samples were formed at high temperature. Table 2 presents the results for pore wall thickness determined by the geometrical considerations using the unit cell parameter (XRD) and pore volume (Broekhoff-deBoer analysis) values, according to the expression developed by Kruk et al. (1997a; 2000):

$$
\mathrm{b}=\mathrm{d}_{(100)}\left\{\frac{2}{\sqrt{3}}-\left[\left(\frac{8}{\pi \sqrt{3}}\right)\left(\frac{\rho \mathrm{V}_{\mathrm{p}}}{1+\rho \mathrm{V}_{\mathrm{p}}}\right)\right]^{1 / 2}\right\}
$$

where $b$ is the pore wall thickness, $d_{(100)}$ is the (100) interplanar distance, $V_{p}$ is the pore volume and $\rho$ is the silica pore wall density, assumed to be equal to the density of amorphous silica $\left(2.2 \mathrm{~g} / \mathrm{cm}^{3}\right)$. From Table 2, it can be seen that the high temperature synthesized samples in fact presented thicker pore walls than the room temperature samples. Estimation of pore wall thickness by other methods $(\mathrm{BJH}, \mathrm{BJH}-$ KJS and BdB) yielded similar results.

Stability tests, in an ammonium acetate buffer solution at $373 \mathrm{~K}$ for 24 hours, were also carried out. It was observed that all samples prepared by at room temperature syntheses underwent total structural collapse, as indicated by comparing the XRD patterns of the samples before and after performing the stability tests. In addition, a sample prepared at $373 \mathrm{~K}$ according to the Beck et al. (1992) procedure colapsed during this stabilization test. However, the 
samples obtained from $373 \mathrm{~K}$ synthesis in the presence of fluoride partially retained their structure. This structure retention was greater for the sample obtained when a gel with a $\mathrm{NH}_{4} \mathrm{OH} / \mathrm{SiO}_{2}$ molar ratio of 8.0 was used $(\mathrm{B}(8-300))$.

Based on the stability tests, gels with a 1.0 $\mathrm{SiO}_{2}: 0.215$ CTABr:8.0 $\quad \mathrm{NH}_{4} \mathrm{OH}: 300 \quad \mathrm{H}_{2} \mathrm{O}$ molar composition were prepared and placed in Teflonlined stainless steel autoclaves at $373 \mathrm{~K}$ for 24,48 and 168 hours. The main objective was testing whether a synthesis carried out at $373 \mathrm{~K}$ during a longer period of time resulted in more hydrothermally stable samples. These samples showed typical XRD patterns of the MCM-41 structure, presenting high order configuration. However, the hydrothermal stability was similar to the sample synthesized at $373 \mathrm{~K}$ for 24 hours.

\section{CONCLUSIONS}

MCM-41 synthesis in fluoride containing media depends on the reaction conditions such as the crystallization temperature and the synthesis gel $\mathrm{NH}_{4} \mathrm{OH} / \mathrm{SiO}_{2}$ and $\mathrm{H}_{2} \mathrm{O} / \mathrm{SiO}_{2}$ molar ratios. Highly ordered MCM-41 samples were obtained for room temperature synthesis with gels presenting the following molar composition: $1.0 \quad \mathrm{SiO}_{2}: 0.215$ CTABr: 3.25-4.3 $\mathrm{NH}_{4} \mathrm{OH}: 300-600 \quad \mathrm{H}_{2} \mathrm{O}$. From syntheses for 24 hours at $373 \mathrm{~K}$, highly ordered MCM-41 samples were obtained with gels possessing the following molar composition: 1.0 $\mathrm{SiO}_{2}: 0.215$ CTABr: 8.0-20 NH $4 \mathrm{OH}: 300 \mathrm{H}_{2} \mathrm{O}$. These samples presented the XRD patterns of a typical MCM-41 hexagonal $P 6 \mathrm{~mm}$ structure, with five diffractions peaks being distinguished. Additionally, the nitrogen adsorption isotherms indicated that a uniform size mesopore system is obtained. Samples synthesized at $373 \mathrm{~K}$ were more hydrothermally stable than those obtained at room temperature, probably because of the presence of thicker pore walls and a more condensed silicate structure.

\section{ACKNOWLEDGMENTS}

This work was supported by FAPERJ (Fundação Carlos Chagas Filho de Amparo à Pesquisa do Estado do Rio de Janeiro, Brazil). FSB and OAL thank the CNPq (Conselho Nacional de Pesquisa e Desenvolvimento Tecnológico, Brazil) for providing scholarships. NUCAT/PEQ/COPPE/UFRJ and CENPES/ PETROBRAS are gratefully acknowledged for performing the XRD and textural measurements.

\section{REFERENCES}

Barrett, E. P., Joyner, L. S. and Halenda, P. P., The determination of pore volume and area distributions in porous substances. I. Computations from Nitrogen Isotherms, J. Am. Chem. Soc., 73, 373 (1951).

Beck, J. S., Vartuli, J. C., Roth, W. J., Leonowicz, M. E., Kresge, C. T., Smith, K. D., Chu, C. T. W., Olson, D. H., Sheppard, E. W., McCullen, S. B., Higgins J. B. and Schlenker, J. L., A new family of mesoporous molecular sieves prepared with liquid cristal templates. J. Am. Chem. Soc., 114, 10834 (1992).

Biz, S. and Occeli, M. L., Synthesis and characterization of mesostructured materials. Catal. Rev. Sci. Eng., 40, 329 (1998).

Brunauer. S., Emmett, P. H. and Teller, E. J., Adsorption of gases in multimolecular layers. J. Am. Chem. Soc., 60, 309 (1938).

Ciesla, U. and Schüth, F., Review: ordered mesoporous materials. Microp. and Mesop. Mater., 27, 131 (1999).

Corma, A., From microporous to mesoporous molecular sieve materials and their use in catalysis. Chem Rev., 97, 2373 (1997).

Guth, J. L., Kessler, H., Caullet, P., Hazm, J., Merrouche, A. and Patarin, J., in: Von Ballmoos, R., Higgins, J. B. and Treacy, M. M. J., Editors, Proceedings of the 9th International Zeolite Conference. Montreal, Butterworth-Heinemann, London, p. 215 (1993).

Kim, W. J., Yoo, J. C. and Hayhurst, D. T., Synthesis of hydrothermally stable MCM-41 with initial adjustment of $\mathrm{pH}$ and direct addition of $\mathrm{NaF}$, Microp. and Mesop. Mater., 9, 177 (2000).

Kresge, C. T. Leonowicz, M. E., Roth, W. J., Vartuli, J. C. and Beck, J. S., Ordered mesoporous molecular sieves synthesized by a liquid-crystal template mechanism. Nature, 359, 710 (1992).

Kruk, M., Jaroniec, M. and Sayari, A., Application of large pore MCM-41 molecular sieves to improve pore size analysis using nitrogen adsorption measurements. Langmuir, 13, 6267 (1997).

Kruk, M., Jaroniec, M. and Sayari, A., Adsorption Study and Structural Properties of MCM-41 materials of different pore sizes. J. Phys. Chem. B, 101, 583 (1997).

Kruk, M., Jaroniec, M. and Sayari, A., Characterization of high-quality MCM-48 and SBA-1 mesoporous silicas. Chem. Mater., 11, 492 (1999).

Kruk, M., Jaroniec, M., Sakamoto, Y., Terasaki, O., Ryoo, R. and Ko, C. H., Determination of pore size and pore wall structure of MCM-41 by using nitrogen adsorption, transmission electron 
microscopy, and X-ray Diffraction. J. Phys. Chem. B, 104, 292 (2000).

Lippens, B. C., Linsen, B. G. and de Boer, J. H., Studies on pore systems in catalysts I. The adsorption of nitrogen; apparatus and calculation. J. Catal., 3, 32 (1964)

Lukens, W. W., Schmidt-Winkel, P., Zhao, D., Feng, J. and Stucky, G. D., Evaluating pore sizes in mesoporous materials: A simplified standard adsorption method and a simplified Broekhoff-de Boer method. Langmuir, 15, 5403 (1999).

Pastore, H. O., Munsignatti, M., Bittencourt, D. R. S and Rippel, M. M., Study on the formation of mesoporous molecular sieves in the presence of various anions. Microp. and Mesop. Mater., 32, 211 (1999).

Ribeiro-Carrott, M. M. L., Estevão-Candeias, A. J., Carrott, P. J. M. and Unger, K. K., Evaluation of the stability of pure silica MCM-41 toward water vapor. Langmuir 15, 8895 (1999).

Ryoo, R. and Jun, S., Improvement of hydrothermal stability of MCM-41 using salt effects during the crystallization process. J. Phys. Chem. B., 101, 317 (1997).
Ryoo, R., Kim, J. M. and Ko, C. H., Improvement of structural integrity of mesoporous molecular sieves for practical applications. Stud. Surf. Sci. and Catal., 117, 151 (1998).

Sayari, A., Periodic mesoporous materials: Synthesis, characterization and potential applications. Stud. Surf. Sci. and Catal., 102, 1 (1996).

Silva, F. H. P. and Pastore, H. O., The synthesis of mesoporous molecular sieves in flouride medium. Chem. Commun., 833 (1996).

Voegtlin, A. C., Ruch, F., Guth, J. L., Patarin, J. and Huve, L., $\mathrm{F}^{-}$mediated synthesis of mesoporous silica with ionic- and non-ionic surfactants. A new templating pathway. Microp. Mater., 9, 95 (1997).

Voegtlin, A. C., Matijasic, A., Patarin, J., Sauerland, C., Grillet, Y. and Huve L., Room-temperature synthesis of silicate mesoporous MCM-41-type materials: Influence of the synthesis $\mathrm{pH}$ on the porosity of the materials obtained. Microporous Mater., 10, 137 (1997).

Xia, Q. H., Hidajat, K. and Kawi, S., Improvement of the hydrothermal stability of fluorinated MCM-41 Material. Mater. Let., 42, 102 (2000). 